\title{
SUPPLY CHAIN CARBON FOOTPRINT TRADEOFFS USING SIMULATION
}

\author{
Sanjay Jain \\ The George Washington University \\ 2201 G Street, NW, Suite 415 \\ Washington, DC- 20052, USA
}

\author{
Erik Lindskog \\ Björn Johansson \\ Chalmers University of Technology \\ Product and Production Development \\ SE-41296 Gothenburg, SWEDEN
}

\begin{abstract}
Supply chain design and operational decisions may impact the carbon footprint of the products flowing through. It is a challenge to determine the carbon footprint and even more challenging to understand the impact of design and operational decisions on the footprint. This paper presents a hierarchical simulationbased approach for estimating the carbon footprint of products flowing through a supply chain. Systems Dynamics simulation is used at a high abstraction level to understand the major factors that may affect the carbon footprint. Discrete event simulation is then used to delve down in detail for evaluating the critical stages in the supply chain. A case study for a closed-loop supply chain of forklift brakes is used as an example of implementation of the approach.
\end{abstract}

\section{INTRODUCTION}

Conscious efforts for reducing the environmental impact of their operations are valuable for progressive companies. Such companies contribute not only to a more sustainable future, but also obtain a competitive advantage. One example from the food and service industry is an award winning restaurant chain in Sweden called MAX. They reported a reduction of their $\mathrm{CO}_{2}$-emissions by $44 \%$ between 2007 and 2008 by evaluating and improving their product value chain (MAX 2008). Market research shows that 13 times more customers relate the MAX brand to environmental friendly products compared to their main competitor. MAX's sustainability manager states that the latter figure is not the result of an increase in traditional marketing, but derives solely from communication of their products' environmental footprint.

Matthews, Hendrickson, and Weber (2008) highlight the importance of determining the carbon footprint across the supply chain and across the life-cycle. They recommend that firms consider the life-cycle footprints from the outset, and "allow the largest sources of carbon emissions along the supply chain to be targeted first and most cost-effectively." Hertwich and Peters (2009) stress that the indirect impacts in supply chains are more important than the direct impacts in the household in their analysis of carbon footprints of nations. Weber and Matthews (2008) show that about 30\% of the carbon footprint of U.S. household consumption is outside the country, that is, the impact is in the international supply chains. These articles stress the importance of consideration of the carbon footprint of the entire supply chain, in particular, the importance of including the international parts of the supply chain.

This paper presents an approach to address the need of organizations to assess the carbon footprint of their products' supply chains and to evaluate alternatives to reduce the footprint. Following the recommendations from the articles cited above, we propose to identify the largest sources of carbon emissions along the supply chain at the outset using system dynamics modeling and then explore cost effective strategies for the largest sources using discrete event simulation. Further following the recommendations, our proposed approach includes consideration of the entire supply chain including international segments if present as part of the configuration alternative. 
Our approach utilizes different simulation software for the purpose rather than life cycle assessment (LCA) or material flow analysis (MFA) software that are commonly used for evaluating environmental impact. We model the necessary material and energy flows within the simulation software instead of combining software for MFA and discrete event simulation for the purpose as implemented by Joschko, Page, and Wohlgemuth (2009). We believe that the effort of building the relevant flows within simulation software is not significantly higher than building the flows in MFA and integrating with simulation software. The key challenge in either case is the collection of the data. Also, the approach of building the flows within simulation software reduces the requirement for the analyst being familiar with MFA and associated software in addition to simulation software.

The next section provides background information on different simulation paradigms and on hierarchical levels in supply chain. Section 3 briefly reviews related work. The proposed approach is presented in Section 4 followed by a case study demonstrating the application of the approach in Section 5. Section 6 concludes the paper with potential future work.

\section{BACKGROUND}

The proposed approach in this paper utilizes models of different simulation paradigms as appropriate for the level of detail in the supply chain hierarchy. The following sub-sections briefly define the simulation paradigms and supply chain hierarchical levels.

\subsection{Simulation Paradigms}

Simulation techniques can be classified using different perspectives. With the perspective of modeling of time, they can be classified as continuous and discrete. From the perspective of representation of the underlying phenomenon, we utilize the following four paradigms described by McLean et al. (2012, p. 2029) that admittedly have some overlaps: system dynamics, discrete event simulation, agent-based simulation, and physical-sciences-based simulation.

System dynamics (SD) modeling and simulation, by design, is aimed at modeling systems at a high level of abstraction for supporting high-level decision making. It has been applied to study a wide range of systems including industrial, social, environmental, financial, and socio-political systems, and their combinations. While generally used to model large systems at high abstraction levels, the strength of modeling feedback loops also allows the technique's application to evaluation of control policies of small electro-mechanical systems. It focuses on modeling causal relationships between key aspects of the system operating under governing policies, especially feedback loops that form beneficial or vicious cycles and determine the overall system behavior. It uses the continuous representation of time.

Discrete event simulation (DES) is suitable for modeling system operations to evaluate system configurations and resource allocations in order to achieve desired system performance or to investigate causes of less than desired performance. It is generally used to model systems at medium to low levels of abstraction. In DES, the operation of a system is represented as a chronological series of events. As the name indicates, it uses discrete event representation of time - the simulated clock time jumps from one event of interest to the next event of interest without going through successive unit increments.

Agent-based simulation (ABS) is suitable for modeling systems where the behavior is determined on the interactions of a large number of independent entities. Example applications include modeling the behavior of a crowd of people affected by an incident, and modeling the spread of a pandemic flu based on the behavior of individuals in the population in the affected area. ABS utilizes a decentralized representation of systems and allows the system behavior to be determined based on defined behaviors of a number of modeled agents. Agent-based simulations may utilize discrete-event or continuous time representation or a hybrid form, i.e., a combination of discrete and continuous representations.

Physical-science-based simulations utilize scientific knowledge, e.g., the laws of physics or mathematical models of observed phenomena to study, understand, or predict the behavior of physical systems. Physical systems can range from a single entity, e.g., in the study of motion of a bullet, to very complex, 
e.g., the behavior of multiple organisms, crowds, or global climate. Physical-science-based models may use mathematical equations and schematic diagrams as conceptual models. They are generally used for modeling at detailed level, that is, at low abstraction level, such as, equipment and equipment component behavior, and behavior of built structures when subjected to explosions in close proximity.

\subsection{Supply Chain Hierarchical Levels}

We propose to analyze the supply chain footprint in a top-down manner along the supply chain hierarchy. The hierarchy is used to allow estimating metrics at a gross level and delving down to finer levels as needed. Supply chains comprise of manufacturing nodes, logistics nodes and links. Our proposed supply chain hierarchy levels for manufacturing, logistics nodes and links are shown in table 1 below. The hierarchical levels defined in the table are for the express purpose of modeling at different levels of detail.

Table 1: Hierarchical levels in supply chain.

\begin{tabular}{|c|c|c|c|}
\hline Level & Manufacturing Nodes & Logistics Nodes & Logistics Links \\
\hline 0 & Supply chain & Supply chain & Supply chain \\
\hline 1 & Manufacturing plant & Distribution centers & Multi-Modal Routes \\
\hline 2 & Lines or areas & Storage areas & Single-mode Routes \\
\hline 3 & Cells or workstations & Storage systems & Route segments \\
\hline 4 & Machines and equipment & $\begin{array}{c}\text { Storage and Material han- } \\
\text { dling equipment }\end{array}$ & $\begin{array}{c}\text { Logistics vehicle (truck, train, } \\
\text { ship, plane, etc.) }\end{array}$ \\
\hline
\end{tabular}

\section{LITERATURE REVIEW}

This section successively and briefly reviews prior related work in the following areas relevant to our effort: carbon footprint definitions, SD simulation for sustainable supply chains, DES for modeling environmental impacts of manufacturing, and hybrid SD and DES models for the same purpose.

There are multiple definitions of carbon footprint. Wiedmann and Minx (2008) discuss multiple definitions of carbon footprint and propose one that focuses exclusively on amount in mass units (kilograms, tonnes, etc.) of carbon dioxide $\left(\mathrm{CO}_{2}\right)$ caused by an activity.

Carbon footprint has been defined in multiple ways even when the focus is on measuring it for supply chains. Sundarkani et al. (2010) apply Eulerian and Lagrangian transport models to model emissions from a supply chain. The emissions are calculated as heat energy released (in $\mathrm{kWh}$ ) due to the greenhouse gases (GHGs) including $\mathrm{CO}_{2}$, methane $\left(\mathrm{CH}_{4}\right)$, nitrous oxide $\left(\mathrm{N}_{2} \mathrm{O}\right)$, sulfur hexafluoride $\left(\mathrm{SF}_{6}\right)$, perfluorocarbons (PFCs), and hydrofluorocarbons (HFCs). Lam, Varbanov, and Klemeš (2010) measure the carbon footprint as the amount of $\mathrm{CO}_{2}$ emitted throughout the supply chain in $\mathrm{kg}$ of $\mathrm{CO}_{2}$. In their analysis of regional biomass supply chains, $82 \%$ of the carbon footprint is due to exploiting and operating the supply chain while remaining is in equipment building and infrastructure construction activities.

World Resources Institute (WRI) and World Business Council for Sustainable Development (WBCSD) have developed a series of Green House Gases (GHG) protocol standards that include guidance of calculating GHG inventories that are commonly referred to as carbon footprint. The Product Life Cycle Accounting and Reporting Standard (WRI/WBCSD 2011) utilizes accounting methodologies established by International Standards Organization's (ISO) LCA standards 14040 and 14044. The guidance calls for calculation of GHG inventory in mass units of equivalent $\mathrm{CO}_{2}$ for the GHGs (including $\mathrm{CO}_{2}$, $\mathrm{CH}_{4}, \mathrm{~N}_{2} \mathrm{O}, \mathrm{SF}_{6}, \mathrm{PFCs}$, and HFCs) using Global Warming Potential (GWP) factor for the conversion for identified unit of analysis (WRI/WBCSD 2011, p. 27).

In the effort reported in this paper, we use the definition of carbon footprint that exclusively considers $\mathrm{CO}_{2}$ emissions following Wiedmann and Minx (2008) and Lam, Varbanov, and Klemeš (2010). The choice of the limited definition of carbon footprint is also motivated by the aim to present the proposed approach with a manageable data collection effort. The proposed approach can be easily used with the carbon footprint definition with a wider scope in future applications. 
SD simulation has been identified as an appropriate modeling tool for sustainable closed-loop supply chains and used to study sustainability in electrical and electronic equipment supply chains by Georgiadis and Besiou (2008). Kumar and Yamaoka (2006) also use SD to study the closed- loop supply chains of U.S. and Japanese auto industries and conclude that government regulations can have a large impact on the reverse supply chains. Vlachos, Georgiadis, and Iakovou (2006) use SD to study closed-loop supply chains for capacity planning and take environmental issues such as legislation and green image into account. While the authors of the above referenced papers address sustainability issues, they do not use the model to calculate the emissions that can be used to measure the carbon footprint. In the SD model presented in this paper, we explicitly include the emissions from each stage of the supply chain to calculate the carbon footprint.

Efforts on modeling environmental effects in discrete event simulation in recent research have been summarized by Herrmann et al. (2011). One benefit of using simulation that is clear in comparison to only modeling environmental effects with traditional LCA is the time aspect and the dynamic behavior of a supply chain in action. The main associated problems with traditional LCA analyses are (Reap et al. 2003):

- The use of lumped parameters and site-independent models.

- Static in nature with disregard of the dynamic behavior of industrial and ecological systems.

- Focus only on environmental considerations, not economic or social aspects.

During model-building and analysis of LCA in combination with DES in Ingvarsson and Johansson (2006), Alvemark and Persson (2007), and Persson and Karlsson (2007) it was recognized that the supply chain and its actors do have a major role in influencing the environmental effects both positively and negatively. By integrating the life cycle of the product at hand utilizing SD these aspects could be more clearly shown and analyzed.

There are few efforts that use a hybrid SD and DES approach for modeling supply chains. In their survey of 127 papers devoted to simulation modeling of supply chains, Tako and Robinson (2012) classified only 3 papers that used the hybrid SD-DES approach for the purpose. Lee et al. (2002) identified presence of continuous and discrete phenomena in supply chains and employed the hybrid approach to show its applicability. Reiner (2005) utilized the hybrid approach to evaluate supply chain process improvements under consideration of customer orientation. Venkateswaran and Son (2005) used the two techniques together for hierarchical production planning with a SD model for enterprise level planning and a DES model for shop floor scheduling. The two models were integrated using the high-level architecture and traded data during run time. Our approach in this paper does not require such run-time integration as we use SD modeling first to get insights that we explore further using DES models.

\section{APPROACH}

Our approach follows a top down analysis path. It is initiated with the supply chain level and delves down in details as warranted by the results of the top level analysis. That is, after the first high-level analysis, the nodes with opportunities for improvement are analyzed at the next level of detail. The opportunities for improvement may be identified based on the size of the carbon footprint associated with the different nodes or based on the ability to control the particular nodes or their respective constituents. The approach can be briefly presented as below:

- Utilize SD modeling to analyze the supply chain at high level. The high-level model utilizes supply chain node level data such as energy consumption and emissions for the factories and logistics links that comprise the chain. At this stage some of the data may be estimated or be based on the data available for generic facilities in on-line data bases. The model at this level should be used for high-level tradeoffs such as alternate supply chain configurations.

- Identify the nodes and links with high apparent opportunity for the reduction of the carbon footprint. If the identified node is a complex operation, a more detailed SD model may be built and 
analyzed to identify the facility or area that provides the highest opportunity among the components of the operation.

- Develop DES models for the identified facility or area. A DES model gives the capability to analyze the production at a lower level than the overall SD model. The amount of details in a DES model is almost unlimited, which makes it possible to study processes in very close detail and investigate uncertain behaviors. The DES model should be used for tradeoffs at the detailed level such as alternate operational policies within the facility or area.

- If the identified opportunity is in an area that involves interactions with multiple people, in particular people from different organizations or customers, an ABS model may need to be developed to explore tradeoffs. For example, an ABS model may need to be developed for evaluating incentives for customers for operating the product in a manner that reduces emissions or to encourage recycling.

- Once the issues have been analyzed with detailed level models, the refined information acquired through these models should be utilized to update the higher level models. This will allow quantifying the impact of changes made at the detailed level on the overall supply chain.

The approach allows flexibility in terms of use of models and interactions among them. The combination of different simulation paradigms allows using each of them in their area of strong applicability, while allowing for efficiency of the effort. SD models can be used with limited data to help identify the nodes where more detailed effort is needed. The approach thus helps avoid the substantial efforts of building detailed models (i.e., DES and ABS) for nodes where it would provide limited benefit. In general, building the SD model will provide an overview of the operation to the analyst that will be beneficial for the development of the DES or ABS models.

Models at different levels of detail across the hierarchy may be loosely or tightly coupled as demanded by the issues being analyzed. The coupling may occur through data. The SD model requires high-level data that generally does not call for a large effort for data collection. If detailed production data is available, it may have to be aggregated for use in the SD model. For example, weekly production data across the year can be recalculated as average monthly production volume. On the other hand, a significant effort is required for building the model and collecting the data for the DES model. If detailed production data is not available, the aggregate data used for SD model may have to be disaggregated. For example, monthly production data may have to be disaggregated into weekly production data using assumptions that are considered reasonable by the production management personnel. The production volumes generated by the DES model will then have to be validated against the aggregate values.

The next section presents a case study that demonstrates the application of the approach.

\section{CASE STUDY}

A forklift brake system supply chain located primarily in Sweden is analyzed for its carbon footprint and associated tradeoffs. The scope of the supply chain goes from cradle to cradle, that is, a closed-loop supply chain starting from steel production, running through manufacturing and use phase, and ending with recycling of used brakes as raw material at the steel plant is considered. Figure 1 shows a representation of a general supply chain in the context of a forklift lifecycle. The successive nodes in the modeled supply chain are listed below:

1. Iron ore mine

2. Steel plant

3. Brake component suppliers

4. Brake manufacturer

5. Forklift manufacturer

6. Industrial user of forklifts

7. Disassembler (recyclable steel components sent back to steel plant as raw material to reduce the need for mined iron ore) 


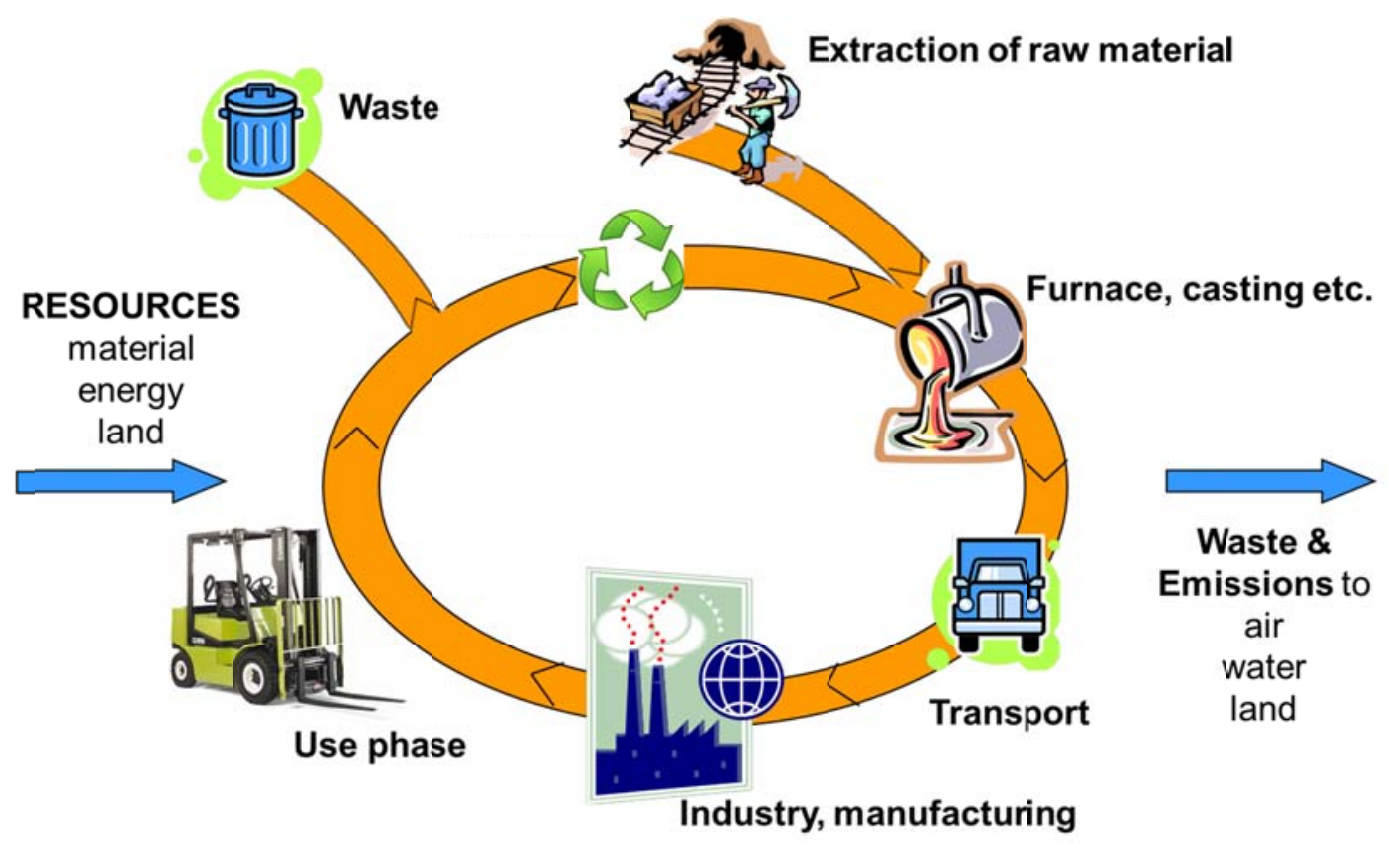

Figure 1: Life cycle of a brake-set.

The following sub-sections discuss the SD and DES models and their respective results briefly. Both the models provide a rich set of outputs. However, only a few outputs were accommodated in the paper to demonstrate the capability to calculate the carbon footprint.

\subsection{Top Level Analysis using SD Model}

\subsubsection{SD Model Description}

The implementation of the approach presented in the previous section starts with the development of a SD model of the supply chain. Figure 2 shows an edited view of the primary part of the SD model developed using Vensim (Ventana Systems, Inc. 2012). All the information arrows have been removed from the primary part of the model to facilitate understanding. As may be noted from figure 2, the model is primarily comprised of stocks and flows, with stocks representing the inventories along the supply chain and the flows representing the conversion and logistics processes. The volumes of the flows for conversion of the product at manufacturing nodes along the supply chain are equated with logistics flows to determine the impact of the logistics activities. This representation thus assumes that the production and logistics transfer batches are the same and they both equal the monthly volume at successive stages. The supply chain is driven by the demand signal comprised of a replacement component for forklifts being retired after completing their useful life and a growth component. The demand signal cascades through the supply chain with actual flows based on the replenishment order sizes at successive stages.

The model uses one brake-set comprising of two front and two rear brakes and wheels as the functional unit of analysis for determination of the carbon footprint. At each manufacturing node the following environmental factors are modeled:

- emissions in production activity

- energy consumption in production (converted to equivalent $\mathrm{CO}_{2}$ emission using the electricity generation source mix in Sweden)

- energy consumption for storage of inventory at the location 


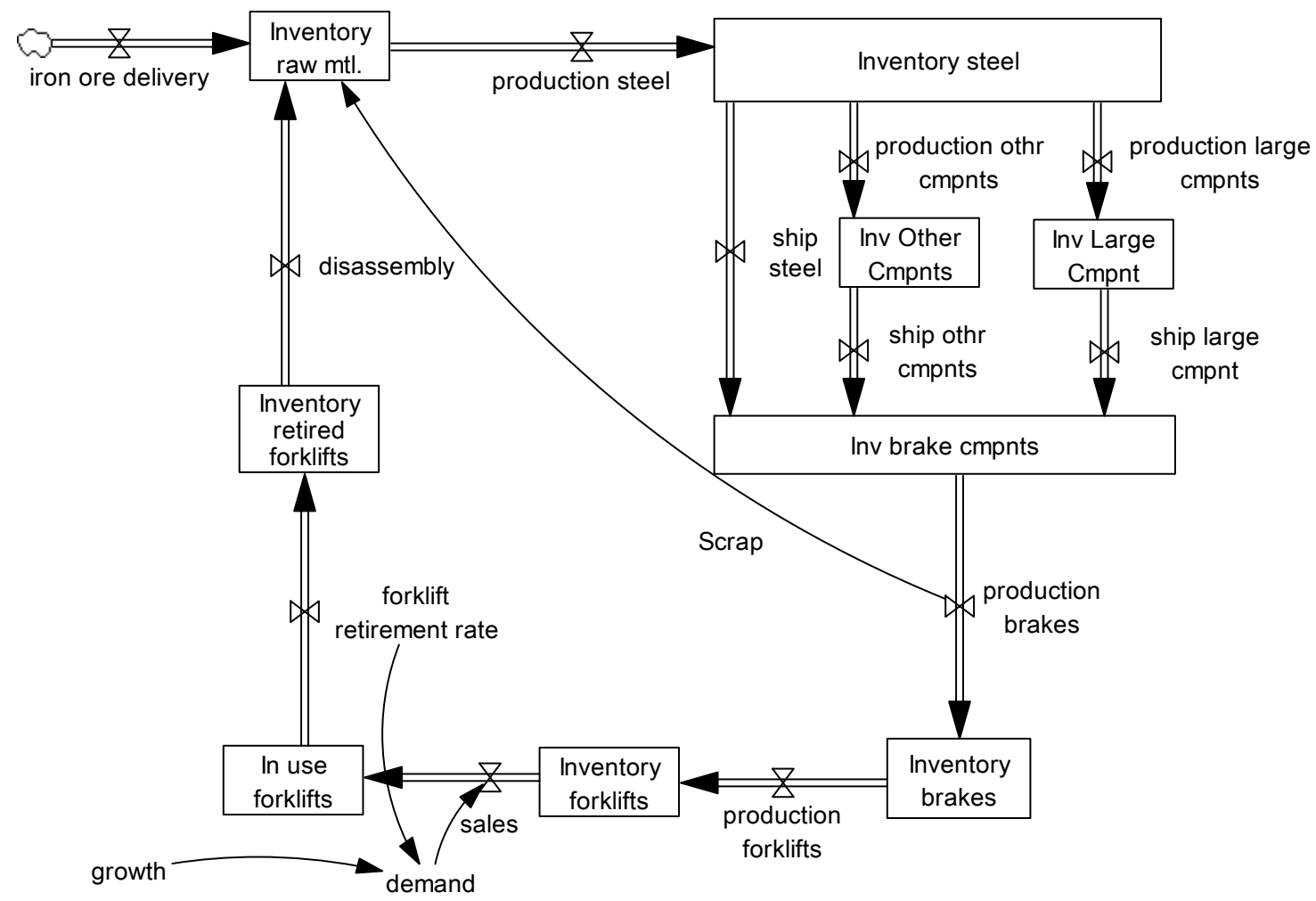

Figure 2: Representation of the supply chain using SD.

In addition, for each transfer between the manufacturing nodes, the following factors are modeled:

- emissions in logistics activity

- energy consumption in logistics (assuming all transfers by trucks)

The data on emissions and energy consumptions were collected at the companies for some of the nodes and projected for other nodes. The identification of $\mathrm{CO}_{2}$ emissions and conversion of energy consumption to equivalent $\mathrm{CO}_{2}$ emissions were based on data from environmental impact databases such as, ELCD (ELCD 2012) and Ecoinvent (Ecoinvent 2012).

\subsubsection{SD Model Results}

The execution of the SD model provided information on the contribution to the carbon footprint from different parts of the supply chain. Figure 3 (a) shows the variations in supply chain carbon footprint over a 10- year period. It shows the stacked contributions of each of the three phases including cradle-to-gate, use phase, and end-of-life, that is, the value for use phase is added on top of the cradle-to-gate phase, and the value for end-of-life phase is added next. The contribution of end-of-life phase is quite small and hence the line representing the additional contribution from this phase runs quite close to the line showing the contribution of the use phase. The variations in the carbon footprint in the cradle-to-gate phase are due to the replenishment policies that initiate production monthly to replenish the inventory used in response to demand traveling across the supply chain.

Figure 3(b) shows the contribution of different life cycle phases to the carbon footprint using a oneyear period value that is calculated as an average over the 10-year data. Note that the value is represented in metric tons in this figure. It is clear that the use phase has the largest carbon footprint among the three major phases of the life cycle. 


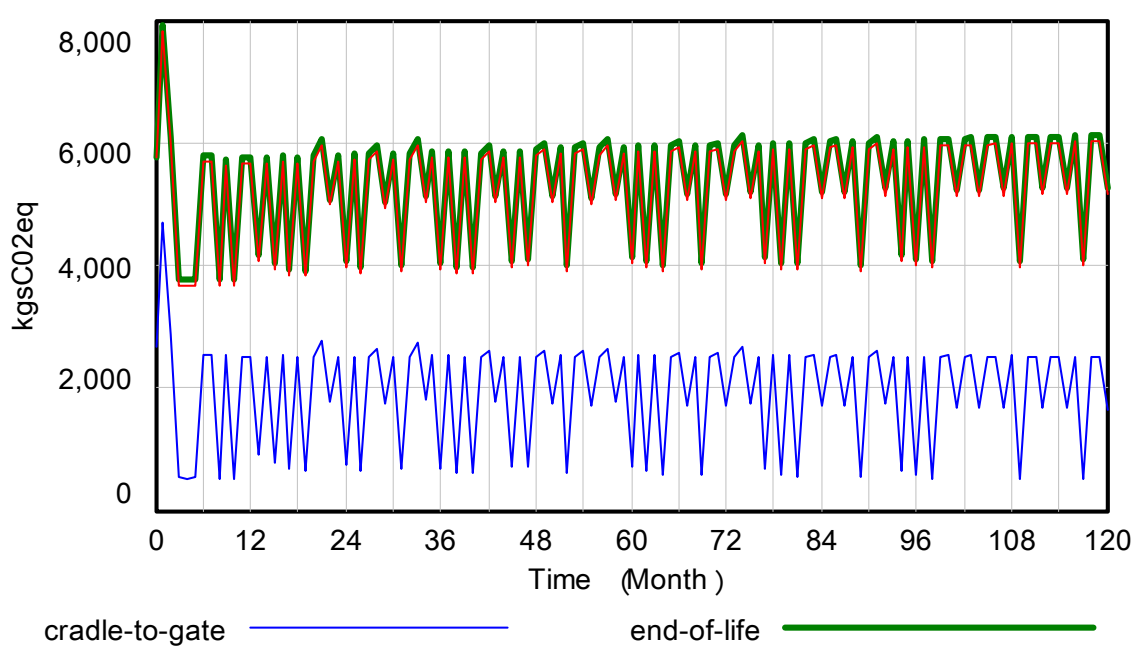

(a)

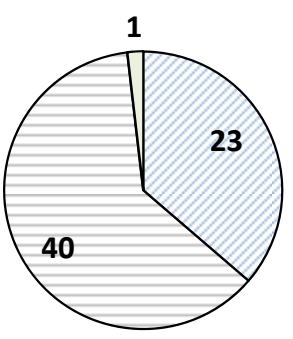

$\square$ Cfp cradle-to-gate

$\square$ Cfp use phase

$\square$ Cfp end-of-life

(b)

Figure 3: (a) Stacked graph of carbon footprint (Cfp) of the supply chain over ten years with contributions of different life cycle phases, (b) Contribution of different life cycle phases to the annual carbon footprint in metric tons of $\mathrm{CO}_{2}$.

\subsubsection{Supply Chain Configuration Tradeoffs}

The SD model of the supply chain provides the capability to study high-level tradeoffs such as the impact of alternate supply chain configurations. The impact of an alternate off-shore supplier on the carbon footprint of the supply chain can be considered with some modifications in the model. The model can be designed to allow for modeling defined alternate scenarios with only parameter changes. For example, the model has been set-up to allow modeling alternate suppliers through changing the shipping delay parameter that in turn updates the in-transit inventory necessary to maintain continuous supply. Similarly, the distance travelled and emissions per unit distance travelled for the mode (ship for an off-shore supplier) are updated to model the carbon footprint contribution of the logistics link from the offshore supplier. It is assumed that the off-shore supplier gets the steel from a plant with the same characteristics as the steel plant for the domestic supplier. If the offshore supplier appears to be an attractive option following the initial analysis, information of their raw material sources can be requested and modeled for a more accurate representation. The use of the off-shore supplier for the largest components in the brake system added 16 metric tons of $\mathrm{CO}_{2}$ emission per year. Figure 4 shows the comparison of carbon footprint of supply chain between the base case with domestic suppliers and the case with offshore suppliers.

The tradeoff facing the brake manufacturer is in terms of cost of the component versus its carbon footprint. Carbon emissions can be converted to monetary value using the carbon allowance that is currently estimated at 100 Swedish Kronor/metric ton (Mölndal Energi 2012), or approximately US $\$ 14 /$ metric ton at current exchange rates. The cost of additional carbon footprint for the off-shore supplier using carbon allowance amounts to only US\$214/year. However, the manufacturer will have to consider the impact of disclosing a larger footprint on its current and potential customers to make a decision. The SD model provides the information to better understand the tradeoff and support decision making.

\subsection{Brake Manufacturer Analysis using DES Models}

The next step in the approach is to delve into details for selected parts of the supply chain. The sponsors of this study had control over the brake manufacturing plant and hence that part of the supply chain was selected for detailed study. The largest contributor to the footprint happened to be the iron ore mine but 
the study sponsors did not have access to the mine's detailed data or influence on its operational policies. Data for the simulation model is based on previous case studies in Lindskog et al. (2011) with some adjustments to fit the SD model approach.

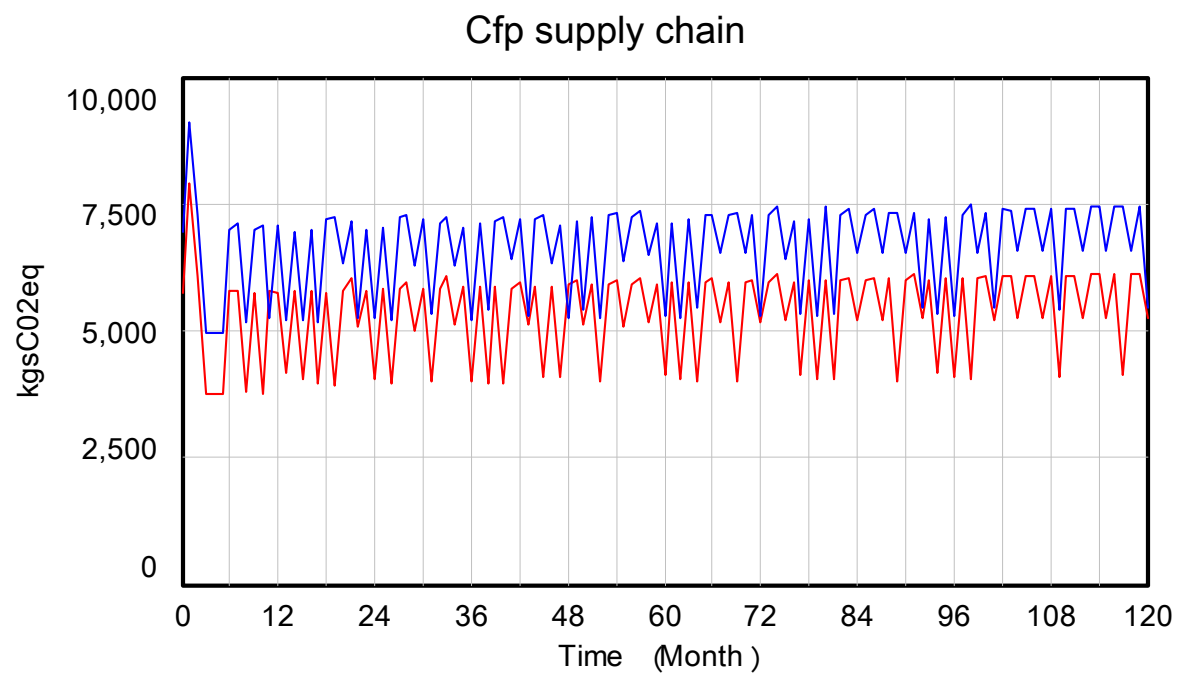

Cfp supply chain : offshore supplier

Cfp supply chain : base case

Figure 4: Comparison of supply chain configurations using the SD model.

\subsubsection{DES Model Description}

The logic of the DES model was designed to determine carbon drivers for each product as it was processed by a resource. Such carbon drivers were for example the electricity consumption for each resource in idle and busy state. The electricity consumption was analyzed individually for all resources in the real production facility by power quality monitoring instruments to get valid data to the model. This approach made it possible to continuously study the carbon drivers during the simulation run for each product individually as well as for the total production. Carbon drivers that did not derive from machine usage, such as heating and cooling fluids, were divided among each product as factory overheads costs. Their contribution to the product was calculated from an overhead percentage based on the product's weight compared with the overall weight for all products. The results were exported to an output spreadsheet after each run to calculate the overall carbon footprint. Environmental data from Life Cycle Inventory databases, raw material data, factory overhead costs, and transport distances were included in the output spreadsheet as static values. Verification of the DES model was done by comparing critical processes in the DES model with the actual production processes. Simulated production data such as lead times were compared with real production data for validation purposes.

\subsubsection{DES Model Results}

The DES model showed that the main emission driver for the production phase was the high energy consumption for the facility. Around $73 \%$ of the total energy was contributed from the overhead cost and not directly related to machine processes for manufacturing products. Overhead energy consumption was mainly due to heating up the factory in winter season as well as having unused machines in stand-by mode. The remaining $27 \%$ was directly related to machine processes and could be separated into energy consumed in two states, idle and busy. The idle state includes times when the product occupies a machine 
without processing, for example setup times and material changes. Approximately $1 / 3$ of the consumed machine energy was a result of the idle state.

In the simulation model it was possible to study each product separately. The analysis on product level revealed unstable behaviors in the model indicated by seemingly large variations in the overall production volumes. Human aspects were shown to be the key contributor to the variability coming from large proportion of manual work with assembling, welding, setting up machines, and internal transports of material. However, human behaviors are quite difficult to simulate, in this case due to lack of standardized work methods.

\subsubsection{Manufacturing Operation Tradeoffs}

One approach to decrease the amount of consumed energy is to reduce times when products are occupying machines in idle state. This is to some extent related to machine setup times when new batches of products need to be processed. An overview of the input data shows that those times are quite long, on average 29 minutes with a maximum of 135 minutes. This in combination with an average energy consumption of $1.44 \mathrm{~kW}$ for machines in idle state results in high energy consumption where the machines could not process any material. By introducing automated setups of the machines, with predefined programs, it would be possible to reduce all setup times to almost zero. The result of such a simulation is shown in figure 5. As could be seen the amount of electricity for idle state is reduced by more than $50 \%$ compared with the initial run. A comparison with the base case is shown in table 2 .

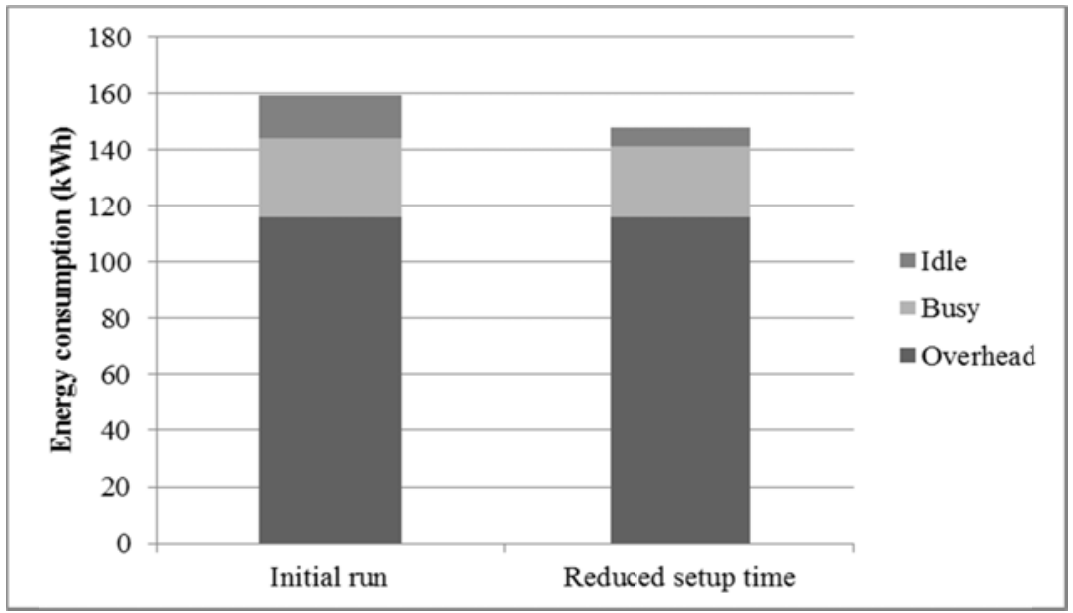

Figure 5: Energy consumption in brake manufacturing - Initial run vs. reduced setup time.

Table 2: Emissions in brake manufacturing - Initial run vs. reduced setup time.

\begin{tabular}{|l|l|}
\hline Simulation run & $\mathrm{CO}_{2}$ emissions \\
\hline Initial & $16.97 \mathrm{~kg} /$ brake-set \\
\hline Reduced setup time & $15.81 \mathrm{~kg} /$ brake-set \\
\hline
\end{tabular}

The approach thus allowed analysis of tradeoffs at the high level using SD simulation and at the detailed level using DES. The case study thus demonstrates the usefulness of the approach.

\section{CONCLUSION}

This paper presented a top down approach for analysis of tradeoffs in supply chain carbon footprints. A case study was used to demonstrate the value of the approach. We plan to extend this work in future by closely coupling the SD and DES models to allow direct communication of information between the two 
models for issues that require run time interaction. We also plan to pursue data sets that allow use of carbon footprint definitions with wider scope rather than just the $\mathrm{CO}_{2}$ emissions.

\section{ACKNOWLEDGEMENTS}

The work of Erik Lindskog and Björn Johansson on this research was funded by a grant from ProViking through the EcoProIT project and by VINNOVA (Swedish Agency for Innovation Systems) through the NFFP5 program. This work has been carried out within the Sustainable Production Initiative and the Production Area of Advance at Chalmers University of Technology, which is gratefully acknowledged.

\section{REFERENCES}

Alvemark, O., and F. Persson. 2007. Flödessimulering av livsmedelsproduktion; Syrade mejeriprodukter [Flow Simulation of food production; Fermented dairy products] - A case study within REELIV, Product and Production Development, Chalmers University of Technology, Reproservice.

Ecoinvent 2012. "Ecoinvent Database." Accessed May 1. http://www.ecoinvent.org/.

ELCD (European Reference Life Cycle Database) 2011. "ELCD Core Database Version II." Accessed May 1. http://lca.jrc.ec.europa.eu/lcainfohub/datasetArea.vm.

Georgiadis, P., and M. Besiou. 2008. "Sustainability in Electrical and Electronic Equipment Closed-Loop Supply Chains: A System Dynamics Approach." Journal of Cleaner Production 16(15): 1665-1678.

Herrmann, C., S. Thiede, S. Kara, and J. Hesselbach. 2011. "Energy Oriented Simulation of Manufacturing Systems - Concept and Application." CIRP Annals - Manufacturing Technology 60(1):45-48.

Hertwich, E.G., and G. P. Peters. 2009. "Carbon Footprint of Nations: A Global, Trade-Linked Analysis." Environmental Science \& Technology 43(16): 6414-6420.

Ingvarsson, A., and C. Johansson. 2006. Flödessimulering av livsmedelsproduktion; Ingemar Johanssons $i$ Sverige $A B$ [Flow Simulation of food production: Ingemar Johansson of Sweden AB] - A case study within REELIV, Product and Production Development, Chalmers University of Technology, Reproservice.

Joschko, P., B. Page, and V. Wohlgemuth. 2009. "Combination of Job oriented Simulation with Ecological Material Flow Analysis as Integrated Analysis Tool for Business Production Processes." In: Proceedings of the 2009 Winter Simulation Conference, edited by M. D. Rossetti, R. R. Hill, B. Johansson, A. Dunkin and R. G. Ingalls, 1456-1465. Piscataway, New Jersey: Institute of Electrical and Electronics Engineers, Inc.

Kumar, S., and T. Yamaoka. 2006. "Closed Loop Supply Chains - A Study of US and Japanese Car Industries." Human Systems Management 25:51-70.

Lam, H.L., P. Varbanov, and J. Klemeš. 2010. "Minimising Carbon Footprint Of Regional Biomass Supply Chains." Resources, Conservation and Recycling 54:303-309.

Lee, Y.H., M. K. Choa, S. J. Kim, and Y. B. Kim. 2002. "Supply Chain Simulation with DiscreteContinuous Combined Modeling." Computers and Industrial Engineering 43(1-2): 375-392.

Lindskog, E., L. Lundh, J. Berglund, T. Lee, A. Skoogh, and B. Johansson. 2011. "A Method for Determining the Environmental Footprint of Industrial Products using Simulation." In: Proceedings of the 2011 Winter Simulation Conference, edited by S. Jain, R.R. Creasey, J. Himmelspach, K.P. White, and M. Fu, 2136-2147. Piscataway, New Jersey: Institute of Electrical and Electronics Engineers, Inc.

Matthew, H.S., C. Hendrickson, and C.L. Weber. 2008. "The Importance of Carbon Footprint Estimation Boundaries." Environmental Science \& Technology 42(16): 5839-5842.

MAX. 2008. Klimatbokslut 2008 (Annual Climate Report 2008). Accessed Jun. 1, 2012. http://www.max.se/download/max_klimatbokslut_2008.pdf.

McLean, C.R., S. Jain, T. Lee, and C.W. Hutchings. 2012. "Technical Guidance for the Specification and Development of Homeland Security Simulation Applications." National Institute of Standards and Technology Technical Note NIST TN-1742. Accessed Jul. 20, 2012. http://www.nist.gov/customcf/get_pdf.cfm?pub_id=910389. 
Mölndal Energi. 2012. "Klimatkompensation" [Carbon offsetting]. Accessed Jun. 1, 2012. http://www.molndalenergi.se/MILJ\%C3\%96/V\%C3\%A5rtmilj\%C3\%B6arbete/Klimatkompensation/ tabid/568/Default.aspx.

Persson, D., and J. Karlsson. 2007. Flödessimulering av livsmedelsproduktion; Kiviks Musteri AB [Flow Simulation of food production; Kiviks Musteri AB] - A case study within REELIV, Product and Production Development, Chalmers University of Technology, Reproservice.

Reap, J., B. Bras, P.J. Newcomb, and C. Carmichael. 2003. "Improving Life Cycle Assessment by Including Spatial, Dynamic and Place-Based Modeling." In: Proceedings of 2003 ASME Design Engineering Technical Conferences and Computers and Information in Engineering Conference. Paper No. 48140. New York, NY: ASME.

Reiner, G. 2005. "Customer-Oriented Improvement and Evaluation of Supply Chain Processes Supported by Simulation Models." International Journal of Production Economics 96(3): 381-395.

Sundarakani, B., R. de Souza, M. Goh, S. M.Wagner, and S. Manikandan. 2010. "Modeling Carbon Footprints Across the Supply Chain." International Journal of Production Economics 128:43-50.

Tako, A.A., and S. Robinson. 2012. "The Application of Discrete Event Simulation and System Dynamics in the Logistics and Supply Chain Context." Decision Support Systems 52(4):802-815.

Venkateswaran, J., and Y. J. Son. 2005. "Hybrid System Dynamic-Discrete Event Simulation-Based Architecture for Hierarchical Production Planning." International Journal of Production Research 43(20): 4397-4429.

Ventana Systems, Inc. 2012. VENSIM Software. Accessed July 16. http://www.vensim.com/software.html.

Vlachos, D., P. Georgiadis, and E. Iakovou. 2006. "A System Dynamics Model for Dynamic Capacity Planning of Remanufacturing in Closed-Loop Supply Chains." Computers \& Operations Research 34: 367-394.

Weber, C.L., and H. S. Matthews. 2008. "Quantifying the Global and Distributional Aspects of American Household Carbon Footprint." Ecological Economics 66:379-391.

Wiedmann, T., and J. Minx. 2008. "A Definition of 'Carbon Footprint'." In: Ecological Economics Research Trends, edited by C. C. Pertsova, 1-11. Hauppauge, NY: Nova Science Publishers.

WRI/WBCSD. 2011. Product Life Cycle Accounting and Reporting Standard. Accessed Jun. 1. http://www.ghgprotocol.org/standards/product-standard.

\section{AUTHOR BIOGRAPHIES}

SANJAY JAIN is an Associate Professor in the Department of Decision Sciences, School of Business at the George Washington University. His research interests are in application of modeling and simulation to complex scenarios including sustainable manufacturing, supply chains, and project management. His email address is jain@email.gwu.edu.

ERIK LINDSKOG is a PhD student in the field of virtual production systems at the Department of Product and Production Development, Chalmers University of Technology, Sweden. Erik is researching mainly on how to visualize and convey information for sustainability considerations while designing and operating manufacturing systems. His email address is Erik.Lindskog@chalmers.se.

BJÖRN JOHANSSON is an Associate Professor in the field of virtual production system and Vice Head of Production Systems division at the Department of Product and Production Development, Chalmers University of Technology, Sweden. He serves as Production Modeling Corporation director for the European office in Gothenburg. His email address is Bjorn.Johansson@chalmers.se. 